\title{
Risk Models for Capital Adequacy: Applications in the Context of Solvency II and Beyond
}

\author{
Peter Liebwein ${ }^{1,2}$ \\ Swiss Re Germany AG, Dieselstraße 11, Unterföhring bei München, München 85774, Germany. \\ E-mail: Peter_Liebwein@swissre.com
}

In the context of the quantitative requirements under pillar 1 of Solvency II, internal risk models quantify a specific company's risk position, that is, measure the risk capital it requires. Because the individual insurance company's situation is modelled, its risk landscape is reflected more accurately than if a standard model approach were used. A brief case study indicates that internal risk models should be used not only to fulfill regulatory requirements, they have to and they do feature more benefits: risk models foster risk management processes; therefore, they are capable of supporting risk-based business decisions. Finally, they constitute a kernel for any risk-based performance measurement framework.

The Geneva Papers (2006) 31, 528-550. doi:10.1057/palgrave.gpp.2510095

Keywords: Solvency II; capital requirement; risk model; risk-based performance measurement

\section{Introduction}

Quantitative models for describing - at least partially - the risk landscape of an insurance company have been in the industry for quite a long time. Some claim that the roots go back even beyond the profit-testing systems of the 1980s. Since that time, several streams have evolved, for example: ${ }^{3}$ integrated risk management, risk-based performance measurement and economic value management, the role of capital in providing insurance protection and its cost. These streams are embedded in a changing environment, for instance: ${ }^{4}$ the perceived need for (quantified) transparency in the context of stakeholder and shareholder information; explicit addressing of principal/agent aspects leading to refined corporate governance; and the convergence of economic evaluations, accounting frameworks and solvency regimes.

There is no point trying to characterize the entire environment of the insurance industry. These introductory statements prove that the Solvency II project is merely a part of the overall picture. Analogously, adequate and customized quantitative descriptions of an insurance company's risk landscape ("internal risk models") are

\footnotetext{
${ }^{1}$ The author thanks Dipl.-Math. Rita Niering, Actuary (head of Ricasso ${ }^{\circledR}$ Centre of Competence) and Dipl.-Nat.wiss. Sandro Kriesch (head of "Risk and Capital" of Swiss Re in Zurich) for their feedback.

2 The paper presented is an extended and updated version of the workshop on this topic at Swiss Re's Nordic Risk and Insurance Summit (NORIS), Copenhagen 31st August 2005.

${ }^{3}$ See Shimpi (1999); Hancock et al. (2001); Scotti (2005).

${ }^{4}$ See Holzheu (2000); Helfenstein et al. (2004); Nebel (2004); G30 (2005); Schiro (2006).
} 
only small elements in a broader context. This paper focuses on quantitative risk models, but endeavours to give some hints that internal models have not been and will not be set up only to fulfill regulatory requirements.

The goal of this paper is to give an overview of internal risk models in the context of Solvency II and some of their applications beyond Solvency II. This can be split into two sub-goals: firstly, the framework for risk models in the context of Solvency II is briefly outlined. Secondly, a brief case study sets the basis for some applications of internal models in the context of determining capital requirements and for some applications that go beyond the primary focus of Solvency II.

The structure of this paper is as follows: the following section establishes the framework for risk models according to the current state of the EU Solvency II project; it concentrates on risk management processes and on solvency capital requirements (SCRs). The next section summarizes some requirements, which will most probably have to be fulfilled by internal risk models. The following section presents a brief case study to illustrate some common approaches to risk modelling in insurance companies. The penultimate section finally states some examples regarding the application of risk models in a broader context. Risk models are key components in evaluating operative risk mitigation strategies, but also in implementing risk-based performance measurement. The last section concludes this paper.

\section{Solvency II and internal risk models}

\section{Risk management process}

According to the latest developments in Solvency II, proper risk management will be required. ${ }^{5}$ Figure 1 differentiates two risk management sub-processes: firstly, "what to do", that is, the core process steps, and secondly, "how to do it", that is, the supportive activities.

The risk management core process can be clustered in a number of ways: ${ }^{6}$

1. Identify actual or potential risk factors, their relationships, and their impact on the company's target variables. Basically, this aims at drawing up a risk map.

2. Quantify these factors, the relationships, and the variables affected in the company.

3. Perform sensitivity analyses according to the impacts on the company's top-level target variables. This helps to separate the "key" or "important" risk factors from those with only minor leverage, that is, to evaluate the risk map and the company's risk position.

4. Identify risk mitigation alternatives and perform steps 1-3 above to analyse the effects of these alternatives, that is, evaluate the various alternatives from the company's risk perspective. Implement the alternatives accordingly (or ensure their effectiveness).

5. Finally, steer the overall risk position by iterating these core process steps.

\footnotetext{
${ }^{5}$ See MARKT/2507/05, p. 4; MARKT/2535/02, pp.55-59; IAIS (2002, p.9, and pp. 32-33); Grünbichler (2004, p. 19). For a broader context see also PWC (2004).

${ }^{6}$ See Liebwein (2000, pp. 15-45).
} 


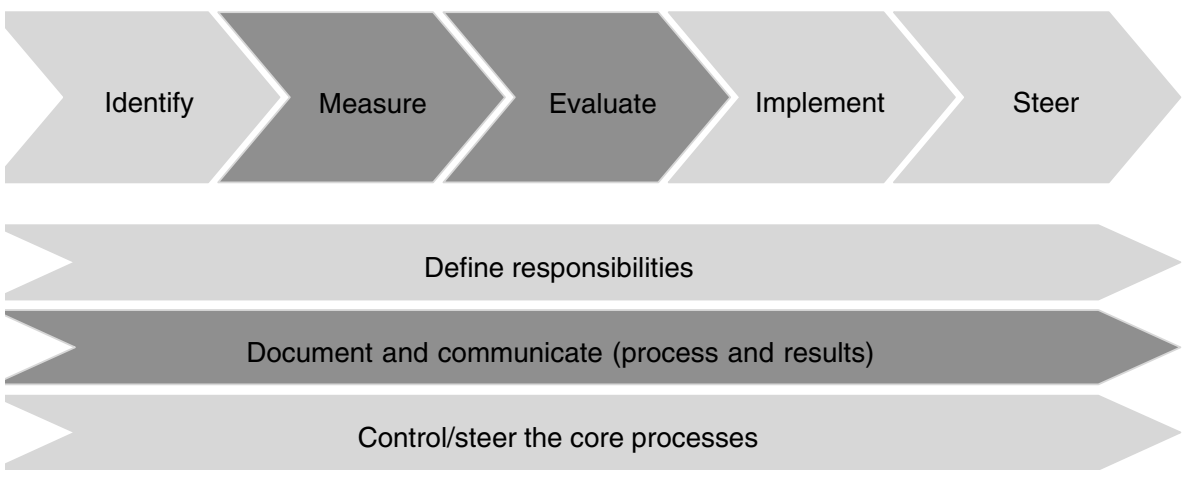

Figure 1. Risk management process with its core activities and supportive activities.

The risk management supportive process bundles all "risk governance" activities:" who does what, when, how often, and what for. This includes documenting and communicating the process itself, as well as the key outcomes of each process step; it should also ensure auditability. Finally, the core process and all other activities have to be steered and controlled.

Figure 1 highlights the process steps in which risk models play a role within this framework: ${ }^{8}$ risk models primarily cover risk factors, risk dependencies, and the overall risk position - at least for the quantifiable elements of the risk map. Thus, risk models certainly play an important role when it comes to risk measurement, evaluating risk positions, and evaluating risk-mitigating alternatives. Risk models also help to communicate the associated results. They should be designed such as to enhance auditability and to facilitate validation procedures.

This is the first connection between risk models and Solvency II - but on a rather general and qualitative basis. The second connection is the one most commonly discussed; it focuses on the quantitative assessment of capital requirements.

\section{Capital requirements}

Solvency II uses a three-pillar approach to structure prudential supervision: ${ }^{9}$ pillar 1 embraces the quantitative requirements; pillar 2 bundles relevant activities for supervising companies' risk management processes; and pillar 3 covers transparency issues (e.g., public disclosure and supervisory reporting). ${ }^{10}$

Within this three-pillar approach, pillar 1 defines - inter alia - capital requirements at two levels. A simple formula, for example, like that of Solvency I, will be used to define the minimum capital requirement (MCR); if capitalization in terms of available

\footnotetext{
${ }^{7}$ Confer IC9 on corporate governance IAIS (2003, pp. 19-23).

${ }^{8}$ See Liebwein (2005, p. 25).

${ }^{9}$ See MARKT/2509/03, p. 7; GDV (2005, p. 16); IAIS (2005, p. 4). See even at an early stage MARKT/ 2535/02, p.33; KPMG (2002, p. 16).

${ }^{10}$ See Hartung (2005).
} 
solvency margin falls below that level, (massive) supervisory actions are taken. ${ }^{11}$ The SCR imposes a higher capital requirement. This requirement basically reflects the capital needed to achieve a certain safety level. ${ }^{12}$ If an insurance company falls below this SCR level, this can be interpreted as an early-warning sign. It therefore supports the company's own risk management function as well as the supervisory activities.

For calculating the SCR, there will be a (nation-wide) calibrated standard model most probably a risk-based-capital model comparable to the U.S. NAIC model. ${ }^{13}$ To generate incentives for developing and using company-specific models, the SCR may alternatively be determined by means of these so-called "internal" models, and the result might be lower (or at least more individual) than that obtained using the standard model.

Therefore, the second connection between internal risk models and Solvency II is twofold:

- As explained above, they can be used to determine the SCR, that is, the economic capital needed on the basis of the company's individual risk position and the specific risk management in place.

- Internal models can also be used to determine some parameters of the standard model. ${ }^{14}$ The interdependencies between different lines of business or the impact of reinsurance on a property and casualty book of business could be examples of such an application. These effects appear to be rather challenging for nation-wide standard models. ${ }^{15}$

This section has briefly characterized the connections between internal risk models and Solvency II with a focus on typical applications. The following section summarizes some requirements and methodological aspects relevant for internal risk models.

\section{Some requirements for internal risk models}

\section{General requirements}

The requirements to be met by internal risk models can be divided into two sub-sets: firstly, general or qualitative requirements, and secondly, more technical requirements regarding specific model specifications. The general requirements for internal risk models in Solvency II have not been finalized so far. However, some studies, ${ }^{16}$ working parties, and institutions ${ }^{17}$ seem to have developed a common understanding to some extent.

\footnotetext{
${ }^{11}$ See CEIOPS (2005, p. 53).

${ }^{12}$ See MARKT/2535/02, pp.48-50.

${ }^{13}$ See CEA (2005); see also Trainar (2006, p. 183-184), and in a general context: Sandström (2004).

${ }^{14}$ See recently CEIOPS (2005, p. 116, pp. 127-128); Ott (2005, pp. 171-184) (with avoidance of "cherrypicking", p. 133); IAA (2004, p. 66).

${ }^{15}$ See Schaub (2006, p. 2).

${ }^{16}$ See e.g. IAA (2004, pp. 64-66); G30 (2005, pp. 95-100); KPMG (2002, appendices pp. 19-20); MARKT/ 2515/02; CEA (2005).

${ }^{17}$ See GDV (2001, pp. 2-4); APRA (2002); BPV (2004); BaFin (2005); CEIOPS (2005, pp. 117-123).
} 
Firstly, an internal risk model has to be integrated into risk management processes, ${ }^{18}$ which should be well defined and adequate. The best case would be if decision-taking can be substantiated on the basis of the given risk model. This should ensure that the information derived from the model is timely and adequate, and can therefore be used for supervision purposes as well. An insurance company might use the results of an internal model for its external risk communication; this is also a strong indication of the integrated character required. ${ }^{19}$ As stated in the general section on risk management processes, an internal model also requires adequate documentation of processes, incomes, algorithms, and outcomes. A prerequisite is that the model framework and its processes and applications have to be "understandable" 20 and the company must train and inform all relevant stakeholders. These aspects enhance risk awareness and the alignment of business functions with corporate risk management.

Secondly, an internal risk model should apply a consistent methodological approach across all lines of business, all business functions, and all risk categories, while still allowing for some specific characteristics. The consistent approach covers especially aspects such as the time horizon and risk measure; the next section discusses some of these aspects.

Thirdly, an internal risk model might need some kind of initial and ongoing approval by the supervisory authorities. A stable and plausible data input process must be set up and made transparent. Furthermore, regular (back-) tests should be performed to prove the validity of the model. ${ }^{21}$ Two aspects should be emphasized in this context:

- Approval does not necessarily imply that the supervisory authority (or its delegates) needs to do full-scale "re-modeling". Supervisors might require that the company itself demonstrate the adequacy of the internal risk model in use and might thereafter focus on the validity of control processes within the company's risk management. $^{22}$

- A simple example of back-testing is to check whether the outcome observed is within a certain range projected, for example, the year before. An outcome outside of this confidence interval is not prejudiced - neither the outcome nor the model. Only if the company lacks a reasonable explanation for this outlier must this be taken as an indication of less-than-adequate risk management processes or inadequate risk models.

To sum up, the general requirements will basically be principle-based and can be characterized as common sense together with clear auditability. The next section discusses some model-specific requirements.

\footnotetext{
${ }^{18}$ See CEIOPS (2005, pp. 117-118); Von Bomhard \& Frey (2006, p. 50), refers to an actuarial model.

${ }^{19}$ See, e.g., Swiss Re (2004, pp. 26-47, pp. 52-55); Munich Re (2005, pp. 18-22).

${ }^{20}$ See Wason $(2005$, p. 5).

${ }^{21}$ According to CEIOPS (2005, p. 132), statistical quality tests, calibration tests, and use tests will be required.

${ }^{22}$ See Ott (2005, pp. 185-222).
} 


\section{Model-specific requirements}

These requirements appear to have attained a more "mature" status than the general requirements. Four aspects need to be pointed out: firstly, what risk categories should be modelled? Secondly, what requirements exist regarding diversification? Thirdly, what activities of an insurance company should be covered? Fourthly, what risk measures and time horizons should be applied?

Firstly, an internal risk model (and a standard model as well) should cover the following risk categories: ${ }^{23}$ underwriting risks (e.g., for life, non-life, reinsurance, pension), market risks (e.g., market-price fluctuations of bonds, stocks, etc.), and credit risk (e.g., credit default on bonds and especially credit exposure regarding reinsurance receivables). Further categories such as operational risks or liquidity risks will most probably be included at a later stage, or will be included under pillar 2 . "ALM risks", and here especially the asset/liability-mismatch risk, ${ }^{24}$ might be included in pillar 1 (see also "total balance sheet approach") and in pillar 2 as well.

Secondly, when aggregating risk positions at a whole-company level, the question of risk dependencies is key. What goes wrong if more things go wrong? Technically speaking, possible concentrations (e.g., regional exposure to natural catastrophes, or exposure to a certain type of industry in asset portfolios) and diversifications have to be taken into account. In this context, reinsurance can have a significant effect on the (net) risk position especially for property and casualty insurance companies. ${ }^{25}$

Thirdly, both the standard model and the internal model follow a total balance sheet approach, ${ }^{26}$ that is, all assets and all liabilities should be covered, taking into account the different maturities or durations of cash flows. Figure 2 puts it in a nutshell: an internal risk model should cover all (relevant) activities of a company and its riskdriving factors. ${ }^{27}$

Fourthly - the most technical aspect - there is the question of risk measure and time horizon: ${ }^{28}$ the (stochastic) variable to be used as a risk measure will be the total result of the company as a whole, maybe including some artificial costs for operational risks. The time horizon will most probably be 1 year, taking into account the maturities of all cash flows. The risk measure - transforming the annual result distribution into a capital figure -will be either value-at-risk (VaR) or tail-value-at-risk (TailVaR). The $\mathrm{VaR}$ is derived from a percentile principle, that is, what capital is needed to safeguard against a certain ruin or loss probability; the TailVaR is the mean, given that ruin or loss situation occurs ("how bad is bad?" 29 ). Two aspects need to be discussed in this context:

\footnotetext{
${ }^{23}$ See CEIOPS (2005, pp. 86-88). See at an early stage Sharma et al. (2002 pp. 22-39). For other classifications see, e.g. IAA (2002, pp. 38-60); KPMG (2002, pp. 20-24); IAA (2004, pp. 29-34).

24 See IAA (2004, pp. 101-102).

${ }^{25}$ An internal model can and should be more detailed than a standard model in terms of this effect. See G30 (2005, pp. 95-100); see most recently Schaub (2006, p. 2).

${ }^{26}$ See IAA (2004, p. 20, p. 24); IAIS (2005, pp. 6-8).

${ }^{27}$ See MARKT/2515/02, pp.4-5; Liebwein (2005, pp. 11-13).

${ }^{28}$ See IAA (2002, pp. 30-31); IAA (2004, pp. 34-35); CEIOPS (2005, pp. 82-85); GDV (2005, p. 20); MARKT/2515/02, pp. 11-12.

${ }^{29}$ Converium (2004, p. 6).
} 


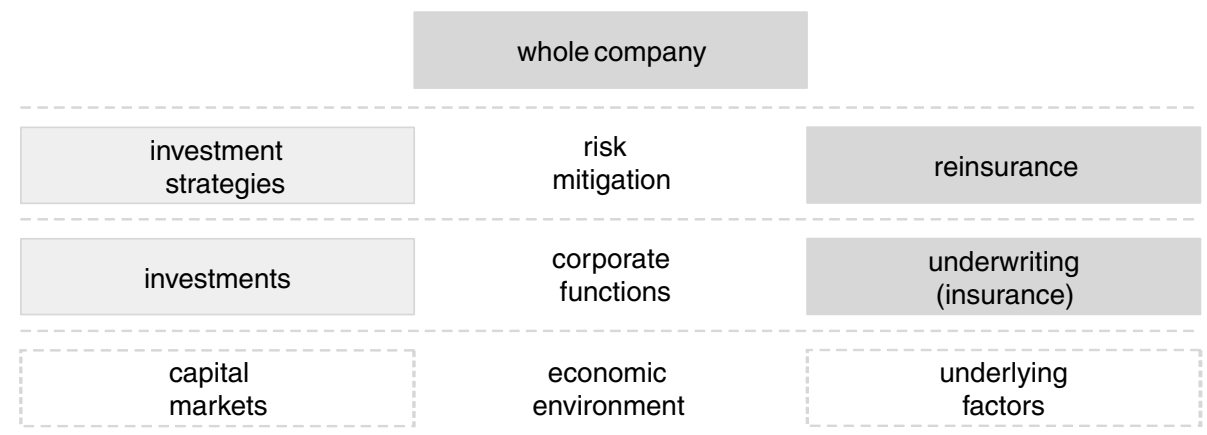

Figure 2. "Total balance sheet approach" covering all activities.

- The discussion about VaR for asset portfolios started with a reference quantile of 1.0 per cent - a simplified notation for an event with a return period of 100 years. The latest proposal seems to be 0.5 per cent, that is, a safety level of 99.5 per cent. ${ }^{30}$ In most situations, the capital requirement strongly depends on the reference quantile, which reflects the risk appetite or the desired safety level. The more the risk measure focuses on rare events, the more it is crucial to have a transparent set of assumptions and an appropriate methodology for estimating the tails of the result distribution.

- There have been some arguments about whether VaR or TailVaR is more appropriate and should be used as the risk measure to determine risk capital requirements. At a first stage, the VaR will probably be preferred. ${ }^{31}$ In the context of an insurance company's risk management, the author recommends applying both of these risk measures. If there is only a minor difference between them (e.g., in some lines of business within life insurance), this suggests a relative stable situation with rather low mass on the tail of the distribution. If the difference between VaR and TailVaR is quite significant (e.g., some exposures to natural catastrophes), this indicates that further analysis is needed, as there are some rare events that could lead to an extremely adverse situation. It is helpful either to explicitly validate the (crucial) assumptions embedded in the model or to intensify risk management focus on this area. This can range from (i) closely tracking observable variables driving the risk position to (ii) implementing specific risk-mitigation strategies.

These discussions on risk measurement must not forget one of the key ideas of the twolevel capital requirement (MCR and SCR): to have an early indicator of when the insurance company (or the supervision authority) should take action to preserve the level of policyholder protection. ${ }^{32}$ An extreme position therefore would be to set an arbitrary risk measure, but to closely track the changes over time. Figure 3 shows an exemplary time series. ${ }^{33}$

\footnotetext{
${ }^{30}$ See CEIOPS (2005, pp. 82-85); GDV (2005, p. 20); Trainar (2006, pp. 180-181).

${ }^{31}$ See CEIOPS (2005, pp. 82-84).

${ }^{32}$ See CEIOPS (2005, pp. 174-177).

${ }^{33}$ See Swiss Re (2004, pp. 52-55); Munich Re (2005, pp. 18-22); Swiss Re (2006, pp. 11-12).
} 


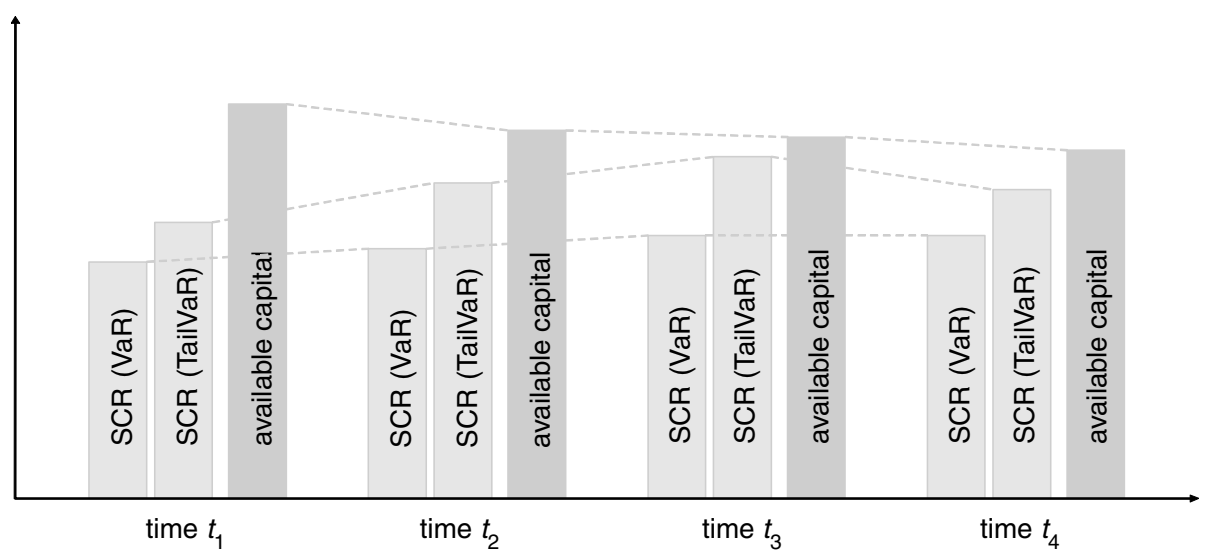

Figure 3. Relative tracking as an early indicator for supervisory or risk management purposes.

What might be worthwhile for an explanation in the first time interval is (i) the increased difference between the $\mathrm{VaR}$ and the TailVaR in terms of required capital and (ii) the decrease in available capital. What might be of interest in the last time interval is the reason for the decrease in required capital in terms of TailVaR. The periodicity with which these figures are provided might be individual: for example, on a regular basis every 2 years and ad hoc, for example, at the supervisory authority's request, in the case of a model change or a change in key risk mitigation strategies (e.g., asset allocation, reinsurance, or business combinations). The lower the capital base, the more it could be of interest to have shorter time intervals. It might also be appropriate to focus on key risk drivers (e.g., interest rates in capital markets) and have a sub-model with faster iterations (e.g., quarterly asset-risk measurements) applied to that specific part. ${ }^{34}$

To highlight the key design principles of internal risk models: ${ }^{35}$

- Realistic assessment of all risks following economic principles, for example, cashflow-based and market-value-oriented.

- Recognition of risk-dependency structures in general, because diversification is a key characteristic of both local and global production of insurance protection.

- Credit for appropriate risk transfer, for example reinsurance and other riskmitigation strategies.

- Risk management has to be core; quantification of risk positions by means of internal risk models is only a part of the overall task.

In addition to these design principles, the framework has to allow for fungibility and capital mobility, especially for insurance groups operating in several countries that have the ability to access resources globally to meet insurance benefit payments.

\footnotetext{
${ }^{34}$ See Liebwein (2000, pp. 40-41).

${ }^{35}$ See also Koller (2005a, b); Von Bomhard \& Frey (2006, pp. 47-49, pp. 54-55).
} 


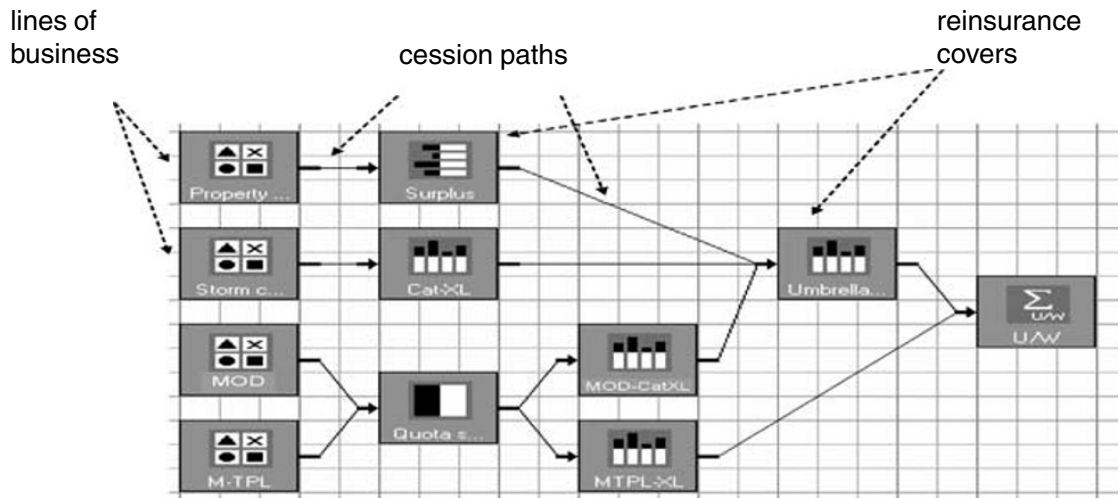

Figure 4. Graphic model representing the structure of the underwriting component.

Localization of capital due to national jurisdictions might work against this and artificially raise capital requirements.

After the foregoing discussion of some requirements, the next section provides a brief case study with typical applications of internal risk models for determining an economic capital requirement.

\section{Case study}

\section{Common model approach to underwriting}

Swiss Re's Risk Capital Simulation Software (Ricasso ${ }^{\circledR}$ ) serves as a guide through the case study. The case study starts with a short introduction into the most commonly used approaches to risk modeling; two components of a typical risk model are introduced: ${ }^{36}$

- Underwriting component with loss models, dependency models, and reinsurance strategies.

- Investment component with asset classes, their stochastic behaviour, and investment strategies.

Figure 4 visualizes the underwriting component and its structure by means of a graphic model. The lines of business cover the key technical items such as premiums, expenses, and losses (incurred and run-off) and induce the stochastic behaviour of the underwriting. Reinsurance as the key risk-mitigation technique is represented as a set of nodes transforming the key technical items into an underwriting result (gross and net).

The nodes for the lines of business cover losses depending on the covered perils and the insured portfolio. These losses are the key stochastic drivers of the underwriting component and are usually disaggregated into three loss types:

- Large single losses, especially for modelling disastrous one-off loss events. Note that per-risk excess of loss reinsurance covers focus on these large losses.

\footnotetext{
${ }^{36}$ See at an early stage KPMG (2002, pp. 35-38). See also Brohm et al. (2001, pp. 9-10).
} 
- Event losses for modelling accumulation scenarios, for example, driven by natural catastrophes. Reinsurance on a per-event basis covers these event losses.

- The remaining part of the total loss burden. This part is usually relatively stable; it is called the basic loss burden or underlying loss burden.

Large and event losses are typically modelled by means of collective models, that is, defining appropriate thresholds, modelling the number of excess losses (loss frequency), and the magnitude of excess losses given that a loss occurs (loss severity). For a business-year view of a multi-year projection, the run-off of loss reserves for past loss events might have to be modelled stochastically too.

A key element of risk modelling for the underwriting function is to model the riskdependency structure. ${ }^{37}$ On the one hand, possible diversification effects are significant drivers of sub-additivity of risk capital requirements, that is, leading to a relief of economic capital needed. On the other hand, possible interdependencies may amplify "singular" adverse events. Typical approaches to modelling dependency structures start in simple cases with linear correlations, which in general potentially underestimate tail dependencies; the other end of the range is to apply copulae, which allow very general dependency structures but are by no means trivial to parameterize on an empirical validated basis. ${ }^{38}$ Some models feature hybrid approaches:

- In the case of large and especially event losses, a loss in one line of business may induce a "consequential loss" in any of the other lines of business. This can be modelled in terms of frequency as well as severity; it allows the tail dependencies to be modelled quite accurately.

- For the remaining basic losses, which are usually rather stable, the dependency structure is modelled by a (linear) correlation matrix.

This methodology implemented in Ricasso ${ }^{\circledR}$ appears to be an appropriate compromise between (i) "sophistification" in modelling capital-driving tail dependencies and (ii) validatable parameterizing at least on a sound basis of expert knowledge. ${ }^{39}$

The key risk-mitigation technique on the underwriting side - especially in non-life insurance - certainly is reinsurance. ${ }^{40}$ An internal risk model focusing on capital requirements, that is, on very rare but adverse situations, has to be as precise as possible in this respect. ${ }^{41}$ This should guarantee adequate modelling of reinsurance effects on the SCR, which in general is not trivial. To achieve numerical stability and to allow for efficient control cycles, predefined standard nodes for all reinsurance structures are favourable. If more complex risk-mitigation techniques are to be applied or analysed (e.g., multiple-trigger solutions), user-defined reinsurance nodes can be specified in most risk-modelling tools.

\footnotetext{
${ }^{37}$ See IAA (2004, p. 75-76); CEIOPS (2005, p. 90).

${ }^{38}$ See e.g. Embrechts et al. (2001).

${ }^{39}$ See IAA (2004, pp. 171-177). See also the beginning section an model-specific requirements under Solvency II.

${ }^{40}$ See IAA (2004, p. 67); see also Sharma et al. (2002, pp. 54-55); IAA (2004, pp. 36-37); CEIOPS (2005, p. 112 , pp. 135-139).

${ }^{41}$ See KPMG (2002, pp. 133-167).
} 
Reinsurance protection can be significant in terms of relieving capital requirements. Therefore, the effectiveness of this risk-mitigation strategy is key, that is, the quantification of reinsurance default risks, which is a major part of the credit risk. In general, two variables per reinsurance partner describe the potential default risk: a probability of default, or of financial distress, and an average recovery in a financial distress situation. Each reinsurance programme can be placed with a large number of reinsurers; this ultimately leads to a compound exposure to reinsurance default risk. This is relevant for long-tail business (financial strength in the long run) as well as for short-tail business (e.g., reinsurers' default in the wake of natural catastrophes).

After having characterized common risk models of the underwriting component, the following section gives an overview of typical risk-modelling approaches for the investment component.

\section{Common model approach to investments}

A typical investment component covers the following areas: firstly, a more or less detailed stochastic behaviour of capital markets, including dependency structures; secondly, a set of asset classes transforming the "outside" stochastic behaviour of capital markets to a stochastic investment result or a stochastic market value of assets; and thirdly, riskmitigation strategies within the asset management either in force or to be analysed.

The following elements can be a starting point for stochastic drivers underlying the investment component: ${ }^{42}$

- Yield curves for various interest rate structures. These yield curves stochastically drive the market value of fixed-income securities.

- Stock prices for stock indices, bundles of stocks, or individual stocks.

- Stochastic dividends materializing as cash flows.

Most risk models follow quite similar approaches on the investment side; thus, there seems to be a pseudo-standard at least for an adequate starting point.

The underwriting component already covers a risk-dependency model for the insurance losses. Some simple approaches to covering dependency models for the investment side could be:

- Different yield curves typically behave in a similar way. These yield curves can be modelled with parallel shifts relative to the basic yield curve.

- Stocks, modelled, for example, with geometric Brownian motions, interrelate according to a (linear) correlation matrix.

- Finally, each stock variable might be correlated with the basic interest-rate structure to model the dependency of fixed-income securities and stock markets.

The dependency of investments and underwriting can be heterogeneous: a simple example could be an inflation-based loss component in long-tail non-life insurance.

\footnotetext{
${ }^{42}$ See IAA (2004, pp. 139-141). For the sake of simplicity, the credit risk of bonds is not taken into account; see IAA (2004, p. 145).
} 
Any "functional dependency" is to be covered by focusing on net cash flows given the underwriting and investment component. An economic valuation of future cash flows for insurance liabilities might refer to certain yield curves; changes in interest rates trigger a re-valuation, especially of fixed-income assets; and a re-evaluation of insurance liabilities. This would allow for quantifying the asset/liability mismatch risk.

At the next stage, the specific investment portfolio of the insurance company is embedded in the stochastic behaviour of these capital market variables. An investment portfolio can typically be split into the following asset classes:

- Deterministic cash position.

- Money-market papers with maturity up to 1 year.

- Bonds with reference to a specific interest-rate environment. The basic characteristics of a bond are face values, maturities, and fixed or floating coupons.

- Stocks with reference to a specific stochastic behaviour and with specification of stochastic dividend payments.

- Real estate is modelled either via a real estate index or deterministically, where cash components and value components might be differentiated.

More sophistication might exist, especially if there is a need to model very specific asset classes or multi-currency environments. The investment portfolio with its asset allocation finally transforms the uncertainty of capital markets into the stochastic behaviour of the investment result, and thus into the overall risk position of the company.

Risk mitigation within the asset management function - either in place or to be analysed - is the last element of the investment component. ${ }^{43}$ Having a 1-year time horizon in mind, it is obvious that capital markets react faster - and so do portfolio managers. Therefore, dynamic risk models make allowance for investment strategies, that is, contingent actions a portfolio manager would take:

- Cash-flow-driven strategies: how should the free positive net cash flow be invested? How should investments be disinvested if net cash flows turn negative?

- Framework strategy (strategic asset allocation): what does the asset allocation look like, should it be stable or stay within certain ranges?

- Price-driven strategies: if the prices of securities decrease to a certain extent, would the portfolio manager sell these titles (or hedge the position)?

- Equity-driven strategies: if the equity base is weakened, for example, due to a major event loss within the underwriting function, then the risk on the investments side has to be reduced, for example, by reallocating more into fixed-income securities.

This model component makes it possible to analyse the risk-mitigating effect of investment strategies. This essentially corresponds to the reinsurance structures on the underwriting side.

\section{Measuring risk capital requirements}

The previous two sections characterized modelling approaches for key operations and their key risk-mitigation strategies. This section discusses an exemplary case to

\footnotetext{
${ }^{43}$ See IAA (2004, p. 34).
} 


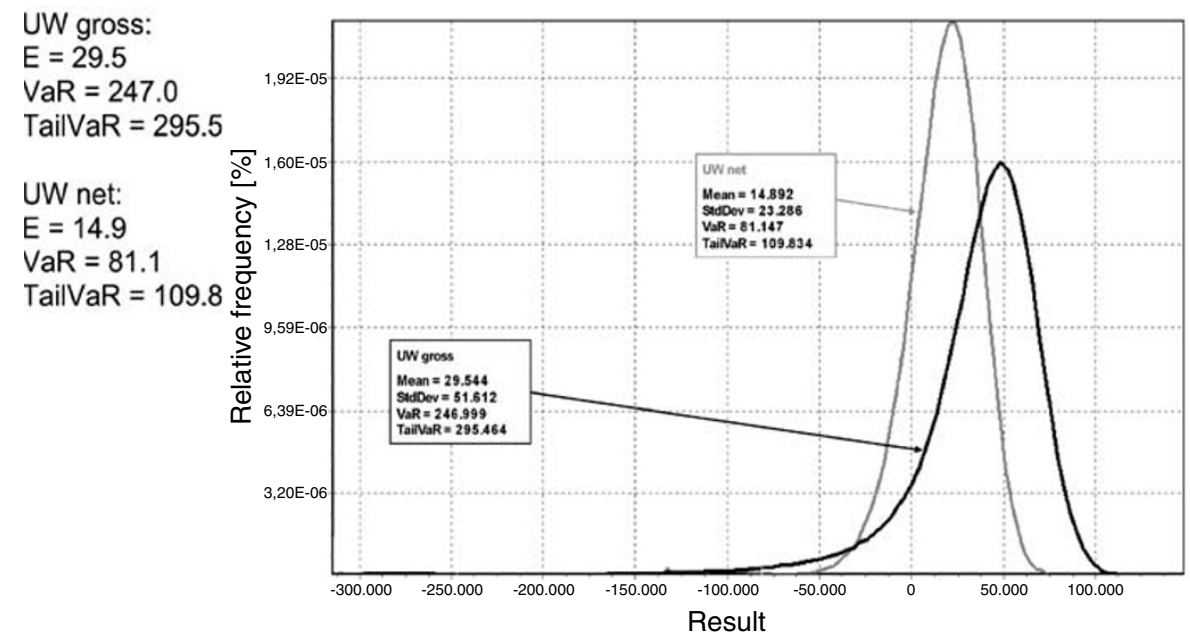

Figure 5. Result distribution and risk measures for underwriting component gross and net.

illustrate typical outcomes that make it possible to determine risk capital requirements. The case study is a simplified Ricasso ${ }^{\circledR}$ analysis for a mid-sized primary insurance company. ${ }^{44}$ In any of the situations analysed, three measures are depicted: the expected value of the annual result; capital requirements in terms of $\mathrm{VaR}$ and in terms of TailVaR, both with 1 per cent-reference quantiles. All outcomes have been simulated with one million runs, which takes approximately 4 minutes.

Figure 4 depicts the structure of the insurance company analysed. The portfolio split is typical of a non-life insurer with a high portion of motor business. It also has some mostly private and commercial - property insurances. Commercial property storm business is modelled separately, due to exposure to European windstorms and its interdependency, for example, with commercial property and motor own damage. The four lines of business are protected by several reinsurance covers: private and commercial property is covered by a surplus reinsurance treaty; commercial property storm is covered by a per-event excess of loss program; the motor lines are reinsured with a motor quota share, followed by a per-event excess of loss on the motor own damage line; and a motor third-party liability excess of loss per risk especially for bodily injury.

The analysis proves that the accumulation problem associated with natural catastrophes is adequately addressed by the existing umbrella cover (per-event protection on property, storm, and motor own damage). Figure 5 shows that the expected result is reduced to half; however, the capital requirements are reduced to approximately one-third. In other words, reinsurance profoundly influences the tail of the distribution and therefore directly affects the capital requirements.

To continue with the exemplary case study, the investment component is included. Table 1 summarizes the asset allocation in place. The insurance company invests

${ }^{44}$ For a more detailed analysis, reference is made to Niering (2006). 
Table 1 Asset allocation of the insurance company

\begin{tabular}{lc}
\hline Asset classes & Split $(\%)$ \\
\hline Real estate & 6.0 \\
Stocks (Europe) & 4.0 \\
Stocks (insurance) & 4.0 \\
Bonds (government) & 50.4 \\
Bonds (corporates) & 33.6 \\
Money market & 2.0 \\
Cash & 0.0 \\
Total & 100.0 \\
\hline
\end{tabular}

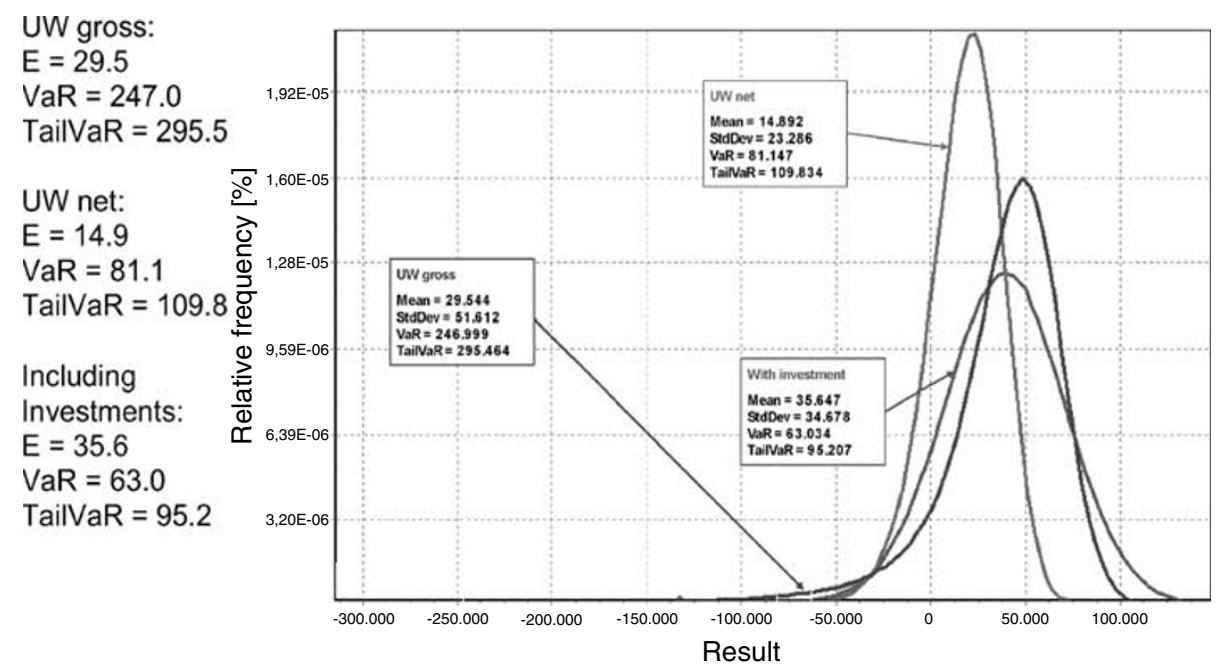

Figure 6. Result distribution and risk measures for underwriting component and investment component.

primarily in fixed-income securities and in stocks; each of these asset classes being divided into two sub-classes. The remainder is allocated to real estate. Two basic investment strategies are defined: positive net cash flows are invested according to the given asset allocation; and negative net cash flows lead to disinvestment in line with the decreasing "tangibility" of asset classes.

Figure 6, finally, shows the total result distribution of the entire modelled company. Without discussing the level of the expected total result, ${ }^{45}$ let us take a look at the relative effect achieved by including the investments: thanks to the positive expected investment result, the net underwriting result is increased by approximately 20 . If the risk position remained the same, the capital requirement (e.g., in terms of TailVaR)

\footnotetext{
45 The relatively high amount of the expected result is basically driven by the magnitude of the loss reserves for past occurrence years in motor third party liability and equalization provisions which correspond to a high volume of assets, producing relatively high investment returns.
} 
would accordingly have been shifted by 20 ; this would have led to a capital requirement of approximately 90 . However, the additional investment risk induced by the investment component increased the risk capital by 5 (roughly speaking from 90 to 95) in relative terms.

The idea of this case study is to show some highlights when measuring risk capital requirements with the aid of internal risk models. If there are questions still open, look at them from a different perspective. Experience proves that the interpretation of the results thus obtained leads to fruitful discussions and to a deeper understanding of the risk landscape and risk drivers. These qualitative aspects in the context of risk awareness already transcend the focus of economic capital requirements in the context of Solvency II. The following section discusses some more issues beyond the primary focus of Solvency II.

\section{Risk models beyond Solvency II}

\section{Risk-based decision support}

Internal risk models can foster an insurance company's risk management, more specifically the measurement of its capital requirement, under pillars 1 and 2 within the Solvency II framework. However, applying internal risk models only for purposes of prudential supervision might lead to an unbalanced cost/benefit relationship. Therefore, the benefits of an internal risk model should be exploited as far as possible. Besides the effect already mentioned (supporting proper risk management as such), two examples of "added value" should be discussed:

- Appropriate risk models can be used to support operative decisions (see this section); this also helps to enhance and sustain a "risk awareness culture".

- Risk models have typically been developed in the context of risk-based performance measurement and risk-based business steering (see the following section).

Two simple examples of decision support will be briefly discussed: firstly, the effect of the umbrella cover in the reinsurance structure is measured; secondly, a different strategic asset allocation on the investment side is analysed. (Figure 4 depicts the reinsurance structure of the insurance company underlying the case study. Table 1 summarizes the associated strategic asset allocation.)

Firstly, not just some specific parameters should be evaluated, but the entire umbrella cover needs to be analysed. Figure 7 summarizes the effect on the underwriting part of the risk position and on the capital requirement.

The net underwriting result distributions look almost alike; therefore, the effect can best be shown by comparing the key parameters: the umbrella cover lowers the expected underwriting result by approximately 2.5. In terms of TailVaR, the umbrella cover reduces the capital requirement by approximately 77 . If the capital cost rate (in terms of economic capital on the basis of TailVaR) amounts to 12 per cent, the capital cost is reduced by approximately 9.2. This means that the expenditure of 2.5 on reinsurance is more than compensated by the reduction in capital cost.

Secondly, a different asset allocation, seemingly more risk-averse, is to be evaluated: Table 2 characterizes the changed split into asset classes (no investments in stock 


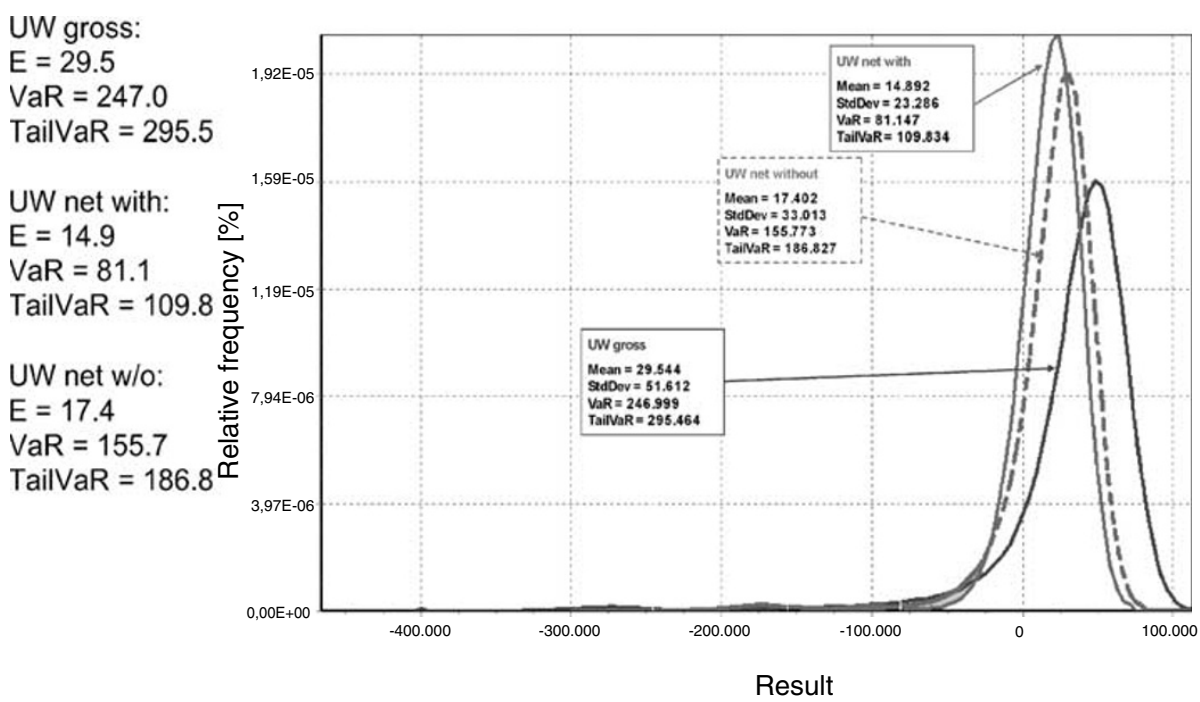

Figure 7. Evaluating a specific reinsurance decision.

Table 2 Alternative asset allocation to asset classes

\begin{tabular}{lcr}
\hline Asset classes & Split $(1)(\%)$ & Split $(2)(\%)$ \\
\hline Real estate & 6.0 & 6.0 \\
Stocks (Europe) & 4.0 & 0.0 \\
Stocks (insurance) & 4.0 & 0.0 \\
Bonds (government) & 50.4 & 55.2 \\
Bonds (corporates) & 33.6 & 36.8 \\
Money-market titles & 2.0 & 2.0 \\
Cash & 0.0 & 0.0 \\
Total & 100.0 & 100.0 \\
\hline
\end{tabular}

markets). Table 3 reflects the different maturities to be analysed (shorter durations for fixed-income securities). Figure 8 shows the associated result distributions.

Figure 8 almost implies a shift in the total result distribution, which would lead to a shift in the expected result and the risk measures. In terms of expected value, the riskaverse strategy misses some five units of expected return, whereas the risk capital requirement in terms of TailVaR remains almost the same. This means that in relative terms the risk position is reduced from as-if 100 to in-fact 95 .

Please note that these results are purely for illustrative purposes; no general statements can be made about the preferability of various strategies. On the contrary, a sound conclusion can only be drawn with the help of an internal risk model applied to the specific insurance company.

As the exemplary case study shows, it is obvious that risk models can be used - inter alia - for calculating an entire company's required risk capital, evaluating and 
The Geneva Papers on Risk and Insurance - Issues and Practice

544

Table 3 Alternative asset allocation to maturities

\begin{tabular}{lccc}
\hline Yield curve & Maturity & Weight $(1)(\%)$ & Weight $(2)(\%)$ \\
\hline Government & 1 & 5 & $\mathbf{6 0}$ \\
Government & 3 & 20 & 0 \\
Government & 5 & 30 & 0 \\
Government & 7 & 5 & 0 \\
Corporates & 1 & 5 & $\mathbf{4 0}$ \\
Corporates & 3 & 10 & 0 \\
Corporates & 5 & 20 & 0 \\
Corporates & 7 & 5 & 0 \\
\hline
\end{tabular}

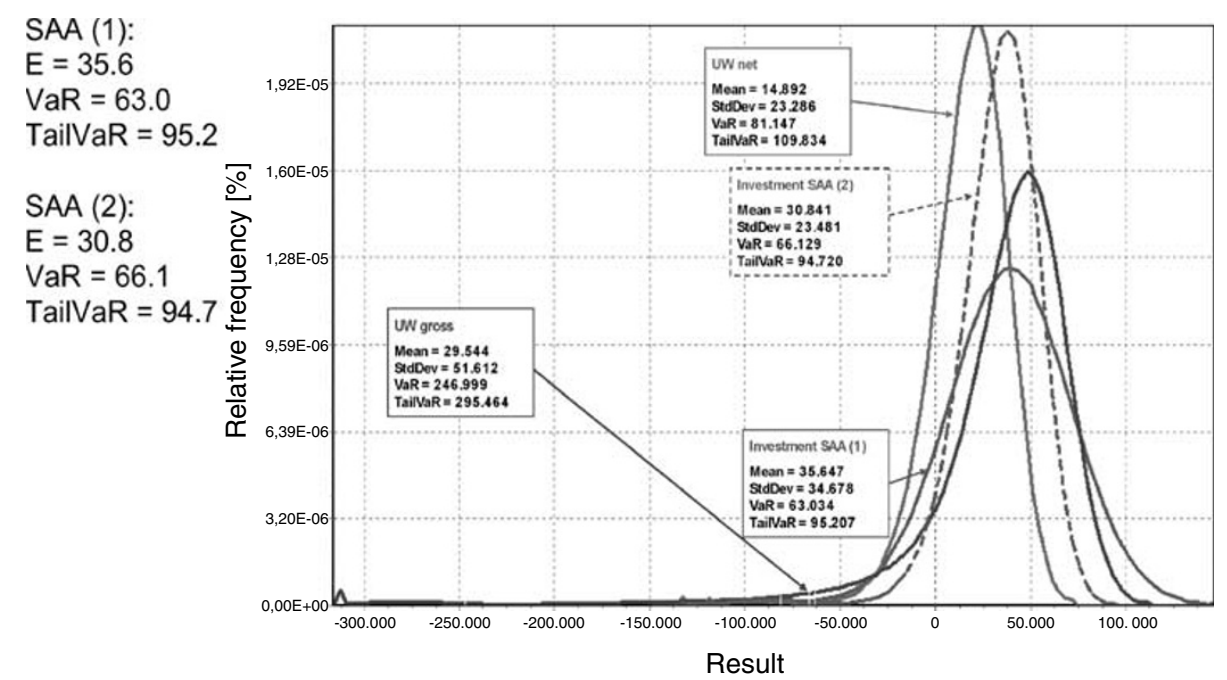

Figure 8. Evaluating a specific strategic asset allocation.

operative structuring of reinsurance or investment strategies. It is not necessary to include all specific actions in one corporate risk model; this might make a system too complex and hence inoperable. An internal risk model covers especially the notion of risk and the methodology of risk measurement; sub-models can be set up in various business functions to support specific decision-taking within a consistent framework.

\section{Risk-based performance measurement}

A second benefit of risk models, and indeed one of the origins of sophisticated risk models, is their application in the risk and performance-measurement framework. ${ }^{46}$ If

\footnotetext{
${ }^{46}$ See Brohm (2002, p. 280).
} 
the capital base is tight, the capital needs to be used most efficiently. In future, boards of directors or senior management might ask questions such as:

- What risk position do we have to accept if we want to achieve a certain expected result?

- What would the expected result be, given a certain maximum tolerated level of risk?

This clearly shows that performance measurement and risk measurement are two sides of the same coin. To put it in other words, a performance measure and a capital measure have to be risk-adjusted and set up consistently.

There are two commonly used risk-based performance measures. For the purposes of business steering, both of them are usually set up on a prospective basis:

- Return on risk-adjusted capital (RoRAC), that is, what is the expected return on the required capital base? An entity stands in good stead if the RoRAC exceeds a certain threshold. The capital requirement, that is, the risk-adjusted capital, is derived from the same result distribution as the expected return in terms of net present value.

- Economic value added, that is, is there still added value after deduction of the cost of the production factor "risk capital"? This cost is reflected in the expected result, just like the cost of the production factor human capital. Within this framework, an entity creates value if the net present value covers the cost of both production factors. Finally, the cost of the risk capital is expressed in terms of a capital cost rate to be achieved on the basis of the capital requirement.

The framework for a risk-based performance measure itself usually has a "fractal characteristic", that is, basically the same risk and performance measure for the entire company is applied to the individual business units. There are three key issues that characterize the specific framework for risk-based performance measurement:

1. Which are the risk-bearing business units subject to risk-based performance measurement? In this context, it is necessary to specify whether the business units are measured with or without dedicated risk-mitigation strategies.

2. How is a business unit's expected result defined? In this context, it is necessary to specify whether and how investment returns should be allocated to the underwriting units generating the cash flows and reserves. It might also be necessary to allocate results of risk-mitigation strategies covering several business units (e.g., reinsurance, asset-based, or insurance-based securitization).

3. How should the diversification effect be allocated to the business units? From a theoretical point of view, this leads to capital allocation principles; from a practical point, there are constraints regarding "understandability". This is crucial, because the capital requirement of a business unit with allowance for diversification depends (i) on its own risk position and (ii) on the diversification effect of this business unit within the entire portfolio of business units.

The most advanced risk-modelling frameworks feature several methodologies that cover typical and most common approaches. For example, risk-bearing business units can be: 
- Only the underwriting result is taken into account; the lines of business then constitute the business units.

- The lines of business and the investment function are the risk-bearing units. Different known methodologies can be specified to allocate investment return to the lines of business.

- Underwriting, investments, and the treasury/ALM function are risk-bearing units. This is the most advanced set up of performance and risk measurement. The risk and return of the underwriting side is benchmarked against a replicating portfolio, that of the investment side is benchmarked against the strategic asset allocation. The ensuing deviations constitute the originated results and characterize the allocated risk capital. ${ }^{47}$

Figure 9 characterizes possible applications for the underlying case study. For the sake of simplicity, only the underwriting function will be discussed here. The risk-based performance measurement framework is characterized as follows:

- The sub-result of the underwriting function is in scope. The underwriting function is measured net of appropriately allocated reinsurance, that is, the key variable of risk and performance measurement is the net underwriting result.

- Each of the lines of business is a risk-bearing business unit subject to risk-based performance measurement.

- Figure 5 has already introduced the (coherent) risk measure: the measure to be applied to the underwriting function and to each of the underwriting business units is the 1 per cent-TailVaR.

- The (coherent) capital allocation principle to be applied is based on the TailVaRs. It basically allocates the risk capital according to a business unit's result contribution in an adverse situation of the underwriting function as a whole.

\begin{tabular}{|c|c|c|}
\hline & whole company & $\begin{array}{l}\text { expected result } \\
\text { capital requirement }\end{array}$ \\
\hline investments & $\begin{array}{l}\text { treasury } \\
\text { function }\end{array}$ & $\begin{array}{l}\text { underwriting } \\
\text { (insurance) }\end{array}$ \\
\hline \multirow[t]{2}{*}{$\begin{array}{l}\text { expected result } \\
\text { capital requirement } \\
\text { (allocated capital) }\end{array}$} & $\begin{array}{l}\text { transfer pricing of funds } \\
\text { (allocated result) } \\
\text { (allocated capital) }\end{array}$ & $\begin{array}{l}\text { expected result } \\
\text { capital requirement } \\
\text { (allocated capital) }\end{array}$ \\
\hline & property & \multirow{4}{*}{$\begin{array}{c}\text { result } \\
\text { contribution } \\
\text { and } \\
\text { capital } \\
\text { allocation }\end{array}$} \\
\hline \multirow{3}{*}{$\begin{array}{l}\text { expected result } \\
\text { capital requirement } \\
\text { (allocated capital) }\end{array}$} & $\begin{array}{c}\text { storm } \\
\text { (commercial) }\end{array}$ & \\
\hline & $\begin{array}{c}\text { motor } \\
\text { own damage }\end{array}$ & \\
\hline & $\begin{array}{c}\text { motor } \\
\text { third party liability }\end{array}$ & \\
\hline
\end{tabular}

Figure 9. Allocating results and risk capital to risk-bearing units. 
Table 4 Some key figures for risk-based performance measurement

\begin{tabular}{lcccccc}
\hline & Property & Storm comm. & MOD & MTPL & Investments & Total U/W \\
\hline Expected premium (net) & 205,546 & 28,502 & 68,572 & 118920 & NA & 421,540 \\
Expected result (net) & 10,873 & -385 & 3,380 & 1,069 & NA & 14,937 \\
Total risk capital requirement & & & & & & 109,817 \\
$\quad$ Capital allocation factors (\%) & 47.87 & 49.05 & 2.59 & 0.49 & NA & 100,00 \\
Allocated risk capital & 52,569 & 53,865 & 2,844 & 538 & NA & 109,817 \\
Expected result on risk capital (\%) & 20.68 & -0.71 & 118.84 & 198.66 & NA & 13.60 \\
$\quad$ Capital cost ratio (\%) & & & & & & 12.00 \\
Allocated capital cost & 6,308 & 6,464 & 341 & 65 & NA & 13,178 \\
Expected result after capital cost & 4,565 & $-6,849$ & 3,039 & 1,004 & NA & 1,759 \\
\hline
\end{tabular}

$\mathrm{NA}=$ not applicable.

Table 4 summarizes some key figures. The risk capital allocation factors are the basis for risk-adjusted performance measurement with allowance for the diversification effect within the underwriting business units. Business units can be compared after taking into account the capital intensity. For example, the relatively high capital intensity of the line of business for commercial storm risks is worth mentioning; by the same token, the relatively low-risk capital requirement for motor third party liability is noteworthy.

Please note that this is based on an example only, the outcomes cannot be generalized. This example is merely intended to illustrate a typical application of internal risk models in the context of risk-based performance measurement. Furthermore, the risk-based view might not be the only perspective of performance and capital management; rating agencies, accounting, or regulatory requirements might also introduce additional elements into management models. However, it is evident from the exemplary case study that risk models constitute a key component within a risk-based performance management framework.

\section{Conclusion}

The aim of this paper was to give an overview of internal risk models in the context of Solvency II. This was split into two sub-goals. Firstly, the framework and background for risk models in the context of Solvency II were set. Solvency II will call for adequate risk management; its three-pillar approach permits and indeed encourages the use of internal risk models. Internal risk models can be used - inter alia - to determine the SCR under pillar 1.

It has been shown that internal risk models can assist in risk management as such and, of course, can help to quantify the company's risk position, that is, to measure the required risk capital from an economic point of view. Because they model the individual company's situation (risk concentration, diversification; specific reinsur-

\footnotetext{
${ }^{47}$ See Hancock et al. (2001, pp. 23-26).
} 
ance structures; specific investment strategies), they reflect the insurance company's risk landscape more accurately than any standard model approach can do.

Secondly, it has been demonstrated - on the basis of a brief Ricasso ${ }^{\circledR}$ case study that internal risk models should not only be used to fulfill regulatory requirements, they have to and they do feature more benefits for relevant stakeholders of an insurance company. Some elements have been discussed as being potential "value adders": internal models support the risk management processes, therefore they are capable of supporting risk-based business decisions (e.g., evaluating and structuring reinsurance, evaluating investment strategies, capital allocation, etc.). Finally, they constitute a kernel for a performance-measurement framework and thus for (riskbased) business-steering concepts.

\section{References}

Australian Prudential Regulation Authority (APRA) (2002) Guidance note GGN 110.2: Internal model based method, from http://www.apra.gov.au/General/General-Insurance-Prudential-Standards-and-GuidanceNotes.cfm (accessed 4th February 2006).

Von Bomhard, N. and Frey, C. (2006) 'Future financial frameworks: Essentials for risk-based capitalmanagement', The Geneva Papers on Risk and Insurance: Issues and Practice 31(1): 46-56.

Bundesanstalt für Finanzdienstleistungen (BaFin) (2005) BaFin white paper on internal models - key issues working paper, Bonn, 11th February 2005.

Brohm, A.L. (2002) Holistische Unternehmensmodelle in der Schaden- und Unfallversicherung: Konstruktion, Analyse, Bewertung und Einsatz im operativen Risiko-Controlling und Risiko-Management, Karlsruhe: Verlag Versicherungswirtschaft.

Brohm, A., Förster, S. and König, A. (2001) Ricasso ${ }^{\circledR}$ : Risk, Capital Management and Reinsurance, Munich: Swiss Re Technical Publishing.

Bundesamt für Privatversicherungen (BPV) (2004) Weissbuch des Schweizer Solvenztests, from http:// www.bpv.admin.ch/dokumentation/00440/index.html?lang = en (accessed 4th February 2006).

Comité Européen des Assurances (CEA) and Mercer Oliver Wyman Limited (2005) Solvency Assessment Models Compared: Essential Groundwork for the Solvency II Project, from http://www.cea.assur.org/cea/ v2.0/publ/de/ouvrage/detail.php?noeud $=4.1 .2 .3 \&$ nbr_article $=\&$ liste_article $=$ \&ouvrage_id $=130 \quad$ (accessed 4th February 2006).

Committee of European Insurance and Occupational Pension Supervisors (CEIOPS) (2005) Answers to the European Commission on the Second Wave of Calls for Advice in the Framework of the Solvency II Project, Frankfurt, October 2005.

Converium (2004) Cycle - What Cycle? How to Not Ride the Roller Coaster, from www.converium.com/ media/20040609_Conv_GoldSachs_pres.pdf (accessed 4th February 2006).

Embrechts, P., Lindskog, F. and McNeill, A. (2001) 'Modelling dependence with copulas and applications to risk management', in S. Rachev (ed) Handbook of Heavy Tailed Distributions in Finance, Amsterdam: Elsevier, pp. 329-384, from http://www.math.ethz.ch/ baltes/ftp/papers.html (accessed 4th February 2006).

Gesamtverband der Deutschen Versicherungswirtschaft (GDV) (2001) Grundsätze für den Einsatz interner Risikomodelle bei Versicherungsunternehmen zur Verbesserung der Finanzaufsicht (Stufe II - Modelle), Berlin, 12th December 2001.

Gesamtverband der Deutschen Versicherungswirtschaft (GDV) (2005) Diskussionsbeitrag für einen Solvency II kompatiblen Standardansatz (Säule I): Modellbeschreibung Version 1.0 vom 01.12.2005, Berlin, 1st December 2005.

Grünbichler, A. (2004) Solvabilität und mehr: Der Weg zur Integration von Risikomanagement und Kapitaladäquanz für Versicherungsunternehmen, presentation on behalf of the Austrian Finanzmarktaufsicht, Vienna, 15th-October 2004.

Group of Thirty (G30) (2005) Reinsurance and International Financial Markets, Washington: Group of Thirty. 
Hancock, J., Huber, P. and Koch, P. (2001) The Economics of Insurance: How Insurers Create Value for Shareholders, 2nd edn, Zurich: Swiss Re Technical Publishing.

Hartung, T. (2005) Aufsichtsrechtliches Überprüfungsverfahren und Marktdisziplin als Instrumente der Versicherungsaufsicht, in Institut für Betriebswirtschaftliche Risikoforschung und Versicherungswirtschaft (ed) INRIVER-Manuscript No. 56, Munich: Ludwig-Maximilians-University 2005.

Helfenstein, R., Scotti, V. and Brahin, P. (2004) 'The Impact of IFRS on the Insurance Industry', Swiss Re Sigma 7, 1-34.

Holzheu, T. (2000) 'Solvency of Non-Life Insurers: Balancing Security and Profitability Expectations', Swiss Re Sigma 1: 1-38

International Actuarial Association (IAA) (2002) Report of the Solvency Working Party: Prepared for IAA Insurance Regulation Committee, February 2002.

International Actuarial Association (IAA) (2004) A Global Framework for Insurer Solvency Assessment, research report of the insurer solvency assessment working party, 2004.

International Association of Insurance Supervisors (IAIS) (2002) Solvency \& Actuarial Issues Subcommittee: Principles No. 5: Principles on Capital Adequacy and Solvency, Tokyo. 9th January 2002.

International Association of Insurance Supervisors (IAIS) (2003) Principles No. 1: Insurance Core Principles and Methodology, Singapore, 3rd October 2003.

International Association of Insurance Supervisors (IAIS) (2005) Solvency \& Actuarial Issues Subcommittee: Towards a Common Structure and Common Standards for the Assessment of Insurer Solvency: Cornerstones for the Formulation of Regulatory Financial Requirements, Vienna, 21st October 2005.

Koller, M. (2005a) 'Looking at an insurer's actual risk situation', Finanz und Wirtschaft, 28th September 2005.

Koller, M. (2005b) 'Firms will benefit from transparency', Insurance Day, 22 November 2005.

KPMG (2002) Study into the Methodologies to Assess the Overall Financial Position of an Insurance Undertaking from the Perspective of Prudential Supervision, Brussels, May 2002.

Liebwein, P. (2000) Strukturierung von Rückversicherungsentscheidungen: Ein entscheidungstheoretisches Modell der Risikopolitik in Versicherungsunternehmen, Karlsruhe: Verlag Versicherungswirtschaft.

Liebwein, P. (2005) Risk and Capital: Some Thoughts on Risk Modeling in Insurance Companies, Zurich: Swiss Re Technical Publishing.

MARKT/2515/02-EN (2002) Risk Models of Insurance Companies or Groups, Brussels: European Commission DG Internal Market, 17th May 2002.

MARKT/2535/02-EN (2002) Considerations on the Design of a Future Prudential Supervisory System, Brussels: European Commission DG Internal Market, 28th November 2002.

MARKT /2509/03-EN (2003) Design of a Future Prudential Supervisory System in the EU: Recommendations by the Commission Services, Brussels: European Commission Internal Market DG, 3rd March 2003.

MARKT/2507/05-EN (2005) Considerations Concerning the Outline for a Framework Directive on Solvency II, Brussels: European Commission Internal Market and Services DG, 23rd March 2005.

Munich, Re (2005) Investors' Day on Risk Management, presentation, London, 27th June 2005.

Nebel, R. (2004) 'Regulations as a source of systemic risk: The need for economic impact analysis', The Geneva Papers on Risk and Insurance - Issues and Practice 29(2): 273-283.

Niering, R. (2006) Risk and Capital: Ricasso ${ }^{\circledR}:$ Risk Capital Simulation Software, Zurich: Swiss Re Technical Publishing.

Ott, P. (2005) Solvabilitätsmessung bei Schaden-Unfall-Versicherungsunternehmen: Anforderungen an stochastische interne Modelle und an deren Prüfung, Wiesbaden: DUV.

Price Waterhouse Coopers (2004) IFRS - Global Reporting Revolution: IFRS and Risk Management, April 2004.

Sandström, A. (2004) Solvency: Towards a Standard Approach, draft 1, 10th September 2004.

Schaub, A. (2006) Letter to CEIOPS, Brussels, 24th January 2006.

Schiro, J. (2006) 'External forces impacting the reinsurance industry: Threats from Regulation', The Geneva Papers on Risk and Insurance - Issues and Practice 31(1): 25-30.

Scotti, V. (2005) 'Insurers' cost of capital and economic value creation: Principals and practical implications', Swiss Re Sigma 3: 1-41

Sharma, P. (2002) Prudential Supervision of Insurance Undertakings, report of the conference of the insurance supervisory services of the member states of the European Union, London, 2002. 
Shimpi, P. (1999) Integrating Corporate Risk Management, Mason, OH: Texere.

Swiss, Re (2004) Investors' Day Presentation, presentation Rüschlikon, Zurich, 23rd November 2004.

Swiss, Re (2006) Annual Report 2005: Summary, Zurich.

Trainar, P. (2006) 'The challenge of solvency reform for European insurers', The Geneva Papers on Risk and Insurance: Issues and Practice 31(1): 169-185.

Wason, S. (2005) Creating a Global Solvency Regime for Insurers: Modeling Challenges and the Role of Actuaries, presentation on 19th October 2005 in Vienna, from http:/www.iais2005.com/presentation/ Panel_Session_03/Wason_Stuart.pdf (accessed 4th February 2006).

\section{About the Author}

Peter Liebwein studied mathematics and earned a doctorate in economics. He published a reinsurance textbook in 2000. He subsequently worked for Swiss Re in the area of risk and performance measurement. Since 2003, he has been responsible for structuring and actuarial assessment of tailor-made reinsurance solutions and has been a member of the Ricasso ${ }^{\circledR}$ Centre of Competence. Since 2005, he has been head of the "Risk and Capital" unit of Swiss Re in Munich. 